\section{Second cousins with cystic fibrosis and no common ancestor who is a carrier}

Park et al, ${ }^{1}$ in this Journal, reported on second cousins with cystic fibrosis (CF) who did not share a CFTR allele identical by descent. They concluded that this situation was 312 times less likely than sharing a CFTR allele inherited from a common ancestor.

Previously we reported on a CF patient from a consanguineous mating (coefficient of inbreeding 0.0215 ) who was a compound heterozygote. ${ }^{2}$ We argued that the frequency of such events could be calculated by solving the equation $\mathrm{Fq} /\left[\mathrm{Fq}+(1-\mathrm{F}) \mathrm{q}^{2}\right]$. In this formula $F$ is the coefficient of inbreeding and $q$ the total frequency of abnormal alleles. The formula was derived from the well known formula to calculate the probability of a particular autosomal recessive disorder in inbred persons, which can be found in numerous textbooks, $\mathrm{Fq}+(1-\mathrm{F}) \mathrm{q}^{2}$. As it turns out, this derivation was obtained by others previously. ${ }^{3}$ In our case, with $q=1 / 60$, the a priori probability of identity by descent of both CFTR alleles was only 0.57

The resemblance of the situation reported by Park et $a l^{1}$ and the one in our report is obvious and the formula derived to calculate the probability of our family can also be applied to the case of Park et al. ${ }^{1}$ In the latter case $F$ does not denote the coefficient of inbreeding but the probability of identity by descent for any given allele in second cousins. With $F=1 / 16$ and $q=1 / 50$ the a priori probability of identity by descent of CFTR alleles in the second cousins reported by Park et al was only $0 \cdot 77$. Therefore, the absence of identity by descent was not 312 times but three times less likely than presence of identity by descent.

It is no wonder that families with unexpected combinations of mutant alleles frequently have $\mathrm{CF}$. First, since $\mathrm{CF}$ is one of the most common autosomal recessive diseases, many families are studied yearly, thus increasing the probability of finding the unusual. Secondly, since in CF the allele frequency q is relatively high, the proportion of exceptional families is also larger than in other autosomal recessive diseases. Thus, in $\mathrm{CF}$ the exceptional is not that exceptional after all.

LEO P TEN KATE Department of Human Genetics, Vrije Universiteit Amsterdam, Van der Boechorststraat 7 , 1081 BT Amsterdam The Netherlands

1 Park VM, Smith ME, Knight MT, Rock MJ. A family study describing second cousins with cystic fibrosis and no common ancestor

2 Ten Kate LP, Scheffer H, Cornel MC, Van Lookeren Campagne JG. Consanguinity sans reproche. Hum Genet 1991;86:295-6.

3 Lander ES, Botstein D. Homozygosity mapping: a way to map human recessive traits with the DNA of inbred children. Science 1987;236: $1567-70$.

\section{BOOK REVIEWS}

If you wish to order or require further information regarding the titles reviewed here, please write to or telephone the BMJ Bookshop, PO Box 295, London WC1H 9JR. Tel 0171383 6244. Fax 0171383 6662. Books are supplied post free in the UK and for BFPO addresses. Overseas customers should add $15 \%$ for postage and packing. Payment can be made by cheque in sterling drawn on a UK bank or by credit card (Mastercard, Visa, or American Express) stating card number, expiry date, and full name. (The price and availability are occasionally subject to revision by the Publishers.)

Transplantation Immunology. Editors Fritz H Bach, Hugh Auchincloss Jr. (Pp 409; $£ 60.00$.) UK: Wiley-Liss, 1995. ISBN 0-47130448-4.

Clinical transplantation of human organs and tissues has experienced rapid growth over the past 30 years and much of our understanding of the immune system has come about by the need to comprehend clinical rejection processes. Any book titled "Transplantation Immunology" must therefore be enticing and when there is a brave attempt to include a chapter on "Molecular biology for the clinician" it becomes very attractive.

Unfortunately this book does not live up to its promise, even though the editors and most of the authors are world leaders. There are four parts to the book covering histocompatibility antigens, graft rejection, clinical transplantation, and frontiers in transplantation and an appendix which introduces the clinician to the basics of molecular biology. So who is this book aimed at: postgraduate students, clinical laboratory scientists, research scientists, or clinicians? This is an issue the editors are themselves concerned with. The outcome is probably no single group, reflecting the diverse contents. The book has clearly been long in production with one author declaring a submission date of June 1993 and therefore needing a "note in proof"; apart from this note I could not find any substantial number of references to publications since 1993.

There is no continuing structure between chapters with some being a presentation of research data (Sorent, "The thymus and self/ non-self discrimination") while others present a good overview with reasoned discussion (Wood and Morris, "The transfusion story and tolerance"). Some chapters have a substantial number of references while others have few.

My own speciality of clinical histocompatibility is covered in two chapters (Lechler, Simpson, and Bach, "Major and minor histcompatibility antigens" and $\mathrm{Au}$ chincloss "Immunological issues in clinical transplantation"). Both lack recent important advances such as use of the PCR for rapid, accurate definition of HLA polymorphisms and ELISA technology in antibody screening. The latter chapter presents only the North
American approach to clinical organ transplantation but the European approach differs greatly. It is rather sad that the author believes sensitisation to HLA antigens cannot be controlled in organ transplantation when there is now convincing evidence to the contrary when HLA mismatching is minimised. The legacy of long term heavy immunosuppression is highly increased malignancy rates, again recently published from several registries but hardly considered here. This raises the important question of the topicality and relevance of other chapters.

In contrast the appendix is a splendid introductory overview of basic molecular biology for clinicians; perhaps the 54 pages should have been published as a separate monograph! There are clear charts and graphics illustrating techniques and biochemical processes but surely the PCR deserves more than one page.

It is not easy to recommend a book costing $£ 60$ without consideration of its value to the individual person. A geneticist wishing to find out about immunological processes in transplantation should not start here. No researcher would find much of value in this book and clinicians would do better to buy one of the several less costly immunology text books leaving some cash spare for an up to date molecular biology text.

PHILIP A DYER

Handbook of Prenatal Diagnosis. Editor R J Trent. (Pp 288; £65.00.) Cambridge: Cambridge University Press. 1995. ISBN $0-521-46060$

The Australian Handbook of Prenatal Diagnosis provides a concise overview of current medical practice in this rapidly developing sphere of medicine.

The Handbook begins with a short historical perspective and a clear summary of its objective: to introduce concepts in prenatal diagnosis to a diverse range of professional readers. Chapter 2 addresses the practice of maternal serum screening for fetal $a b$ normality; neural tube defects and Down syndrome are individually discussed in detail. The principles are coherently explained, but screening and diagnostic tests are not clearly distinguished in the general section. Chapter 3 provides an illustrated summary of congenital malformations which are detectable by ultrasound scanning, but another text should be sought if detailed or technical information is required. The role of invasive procedures, including the indications and complications of amniocentesis, chorionic villus sampling, and fetal blood sampling in prenatal diagnosis are briefly discussed in chapter 4 , which provides a useful checklist for counselling in busy clinical situations. Chapters 5 and 6 describe with clarity the applications of cytogenetic and molecular genetic technology to prenatal diagnosis and would provide a helpful introduction for readers without laboratory experience. Chap ter 7 reviews the diagnosis, prevention, and management of infectious diseases in the fetus and neonate and serves as a reminder that environmental factors may mimic or complicate genetic disease. There is a departure from the general theme of a handbook in chapter 8 , in which the strategies for prenatal 